\title{
Bubble Trails, Bursts, Rings, and More: A Review of Multiple Bubble Types Produced by Cetaceans
}

\author{
Kelsey R. Moreno ${ }^{1,2, *}$ and Riley P. Macgregor ${ }^{1}$ \\ ${ }^{1}$ Marine Mammal Behavior and Cognition Lab, University of Southern Mississippi \\ ${ }^{2}$ Zoology Department, Tel Aviv University \\ *Corresponding author (Email: Kelsey.R.Moreno@gmail.com)
}

Citation - Moreno, K. R., \& Macgregor, R. P. (2019). Bubble trails, bursts, rings, and more: A review of multiple bubble types produced by cetaceans. Animal Behavior and Cognition, 6(2), 105-126. https://doi.org/10.26451/abc.06.02.03.2019

\begin{abstract}
Reports of cetacean bubble production spanning several decades have begun to document occurrences and possible functions of this unique behavior. These observations can be grouped by their physical features into three main categories: bubble trails, bubble bursts, and bubble rings, though some observations indicate the need for additional categories and others simply report on bubbles generally. Bubble trails consist of a long, thin stream, and are often seen in stressful situations, agonistic interactions, to initiate synchrony, and with vocal behaviors. Bubble bursts consist of a large volume of air in a cloud-like clustering, and are primarily observed in agonistic situations or attributed to surprise, excitement, interest, or curiosity. They are also seen in sexual and other social situations. This category may include a less commonly reported type, the large singular bubble. Bubble rings consist of air forming a torus, and are almost exclusively produced as objects for play, with exceptions occurring during agonistic interactions. Additional possible types include scant bubble or blowhole drip, and bubble cloud from the mouth. Much is still unknown regarding bubble functions, most notably whether production is voluntary. In this review, we summarize findings throughout the literature, including terminology and behavioral use. We also discuss issues within the literature and provide suggestions for future research. Through this, we hope to improve understanding, encourage more studies and descriptions of bubble production, and ultimately support using bubble production as an indicator behavior for practical applications, including welfare and conservation.
\end{abstract}

Keywords - Bubble, Bubble trail, Bubble burst, Bubble ring, Cetacean behavior

Cetaceans produce bubbles by releasing air underwater from their respiratory tract through exhalation. Due to their unique life history as air-breathing animals that spend the majority of their time underwater, they are able to utilize bubble production more readily than other taxa can. The extent to which bubble production is under conscious control is unknown, and likely varies by bubble type and context. Most of what is known about bubble production comes from reports across several species of cetaceans, and it appears to play an important role in a number of situations.

Bubbles can take on a range of forms and serve a variety of functions. One of the more welldocumented uses of bubble production is as a component of foraging to facilitate prey capture, such as in humpback whales (Megaptera novaeangliae; Hain, Carter, Kraus, Mayo, \& Winn, 1981; Sharpe \& Dill, 1997; Wiley et al., 2011), Atlantic bottlenose dolphins (Tursiops truncatus; Fertl \& Wilson, 1997), Atlantic spotted dolphins (Stenella frontalis; Fertl \& Würsig, 1995), false killer whales (Pseudorca crassidens; Zaeschmar, Dwyer, \& Stockin, 2013), and orcas (Orcinus orca; Similä \& Ugarte, 1993; Visser et al., 2008). Bubbles may also be created and then used as manipulatable objects during play, and, 
because of ease of observations, have mostly been reported in individuals under human care (e.g., Delfour \& Aulagnier, 1997; Jones \& Kuczaj, 2014; McCowan, Marino, Vance, Walke, \& Reiss, 2000; Paulos, Trone, \& Kuczaj, 2010).

There are many instances of bubble production that are not generated as objects to form barriers or be manipulated. Several authors agree that these bubbles are likely used as a communicative signal (e.g., Herzing, 2000; Pryor, 1990), but it is possible bubble production may instead be a physiological response or by-product of other behaviors. What little is known about its function is limited to interpretations of observational instances.

\section{General Background}

Early reports describe bubbles in general terms, not distinguishing between types of bubble emissions. These reports suggest bubbles appear in different contexts and often co-occur with other behaviors. One example includes a description of an aggressive encounter between bottlenose dolphins residing in managed care, involving head-to-head positioning, vertical head jerks, burst-pulse sounds, and bubbles (Overstrom, 1983). Similarly, Dudzinski (1998) reports that, in wild spotted dolphins, bubbles are produced in conjunction with s-postures, intense vocalizations, and aggressive contact behaviors. It is also noted that bubble blows, another general term for bubble emissions, are strongly associated with aggression, as well as object play with seaweed, in wild Hector's dolphins (Cephalorhynchus hectori; Slooten, 1994). The author suggests bubbles may be used to add emphasis to other behaviors depending on the context (Slooten, 1994).

Bubbles have also been observed as a behavioral response to stimuli. Bubble blows were reported in orcas and false killer whales during exposure to a mirror (Delfour \& Marten, 2001). A young female orca bubbled in front of the mirror and increased bubble production for the first week of exposure. A male false killer whale produced bubbles when swimming by the mirror or bumping his head against it (Delfour \& Marten, 2001). The authors mention that bubbles are often interpreted as signs of interest and/or excitement, though it is possible the behaviors observed in this study fit into a different context than what was interpreted, such as agonism. Additionally, a recent publication concluded that general bubble production is one of many behaviors that increase in response to provided stimuli (Hanna et al., 2017). These reports on bubble production have presented information about proposed functions for general bubble production behavior in cetaceans.

Other researchers have operationally defined different bubble behavior types, allowing for identification of characteristic structures. The current commonly recognized bubble types are bubble trails, bubble bursts, and bubble rings (Table 1). Additional reported bubble types include the scant bubble, also called a blowhole drip, and bubbles released from the mouth (Table 1). These observations have also served to identify the many situations where each of these bubble types are used, including agonistic, synchronization, sexual interaction, and response to unfamiliar stimuli (Table 1). Many of these contexts are associated with high levels of arousal, indicating bubbles may be linked to internal states. However, the existence of bubble types with starkly contrasting features and overlapping, but not interchangeable, usage indicates context and other factors also play a role in bubble production.

In this review, we discuss findings on all commonly recognized bubble production types and other bubbles that do not fit into one of these three categories. For each bubble type, we describe and aim to clarify the terminology used throughout the literature, discuss evidence for proposed behavioral functions and differences in use between demographic groups, consider the evolutionary origin of bubble bursts, and suggest future directions for research on the behavioral functions of bubbles. 
Table 1

Summary of Bubble Production Types, Terminology, and Context

\begin{tabular}{|c|c|c|c|}
\hline Bubble Type & Alternative Names & Context & Citation \\
\hline \multirow[t]{4}{*}{ Bubble Trail } & \multirow{4}{*}{$\begin{array}{l}\text { Bubble Stream, } \\
\text { Whistle Trail, Bubble } \\
\text { Blow, Bubble Column, } \\
\text { Bubble Train }\end{array}$} & $\begin{array}{l}\text { Stress, Distress, or } \\
\quad \text { Aversion }\end{array}$ & $\begin{array}{c}\text { Bowles \& Anderson, 2012; Herzing,1996, 2000; Kuczaj et } \\
\text { al., } 2015\end{array}$ \\
\hline & & Agonistic & $\begin{array}{c}\text { Baker \& Herman, 1984; Dudzinski, 1996, 1998; Herzing, } \\
\text { 1996; Lusseau, 2006; Tyack \& Whitehead, 1982; Wood, } \\
1953\end{array}$ \\
\hline & & Synchrony & Trudelle, 2010; Visser et al., 2008 \\
\hline & & General Social & $\begin{array}{l}\text { Beard, 2007; Bowles et al., 2015; Dudzinski, 1996; Fripp, } \\
\text { 2005; McCowan et al., 2000; Moreno, 2017; Pryor, } 1990\end{array}$ \\
\hline \multirow[t]{4}{*}{ Bubble Burst } & \multirow[t]{4}{*}{$\begin{array}{l}\text { Bubble Cloud, } \\
\text { Underwater Blowing }\end{array}$} & Threat or Agonistic & $\begin{array}{l}\text { Baker \& Herman, 1984; Bowles \& Anderson, 2012; } \\
\text { Dudzinski, 1996; Helweg et al., 1992; Herzing, 1996; Hill } \\
\text { et al,. 2011; McCowan et al., 2000; Moreno, } 2017\end{array}$ \\
\hline & & $\begin{array}{l}\text { Surprise, Excitement, } \\
\text { Interest or Curiosity }\end{array}$ & $\begin{array}{l}\text { Delfour \& Marten, 2001; Lilley et al., 2018; Marten et al., } \\
\text { 1996; McCowan et al., 2000; Moreno, 2017; Pryor, } 1990\end{array}$ \\
\hline & & Sexual & Baker \& Herman 1984; Herzing, 1996; Moreno, 2017 \\
\hline & & General Social & Hill et al., 2011 \\
\hline \multirow{4}{*}{$\begin{array}{l}\text { Potential } \\
\text { Bubble Burst } \\
\text { Subtype }\end{array}$} & \multirow{4}{*}{$\begin{array}{l}\text { Large singular bubble, } \\
\text { Big underwater bubble }\end{array}$} & Agonistic & Dudzinski, 1998; Shane, 1990 \\
\hline & & Object for Play & McCowan et al., 2000 \\
\hline & & Response to Object & Clark et al., 2013 \\
\hline & & Foraging & Trudelle, 2010 \\
\hline \multirow[t]{2}{*}{ Bubble Ring } & \multirow[t]{2}{*}{ Bubble Torus } & Object for Play & $\begin{array}{l}\text { Gewalt, 1989; Hill, 2009; Marten et al., 1996; McCowan } \\
\text { et al., 2000; Pace, 2000; Paulos et al., 2010; }\end{array}$ \\
\hline & & Agonistic & Herzing, 1996, 2000; Pryor, 1990; Pryor \& Kang, 1980 \\
\hline \multirow[t]{2}{*}{ Scant } & \multirow[t]{2}{*}{ Blowhole Drip } & $\begin{array}{l}\text { Investigation; Close } \\
\text { Social Interaction }\end{array}$ & Moreno, 2017 \\
\hline & & Playful & Canisius College, 2015 \\
\hline Mouth Cloud & Bubble cloud & General Social & Baker \& Herman, 1984; Reidenberg \& Laitman, 2007 \\
\hline \multirow[t]{3}{*}{$\begin{array}{l}\text { General } \\
\text { Bubbles }\end{array}$} & \multirow[t]{3}{*}{$\begin{array}{l}\text { Bubble Blow, } \\
\text { Bubbles, Bubble } \\
\text { Emissions, Bubble } \\
\text { Release, Bubble } \\
\text { Productions }\end{array}$} & Agonistic & Dudzinski, 1996, 1998; Overstrom, 1983; Slooten, 1994 \\
\hline & & Response to Object & Delfour \& Marten, 2001; Hanna et al., 2017 \\
\hline & & Play & Delfour \& Aulagnier, 1997; Slooten, 1994 \\
\hline
\end{tabular}




\section{Bubble Trails}

\section{Terminology}

Bubble trails are iconic and widely reported in the literature. Their form consists of a long, thin stream of bubbles (Figure 1) that can be single streams or multiple visually distinct streams separated by very short intervals, referred to as a bubble trail bout (Beard, 2007). The two most common alternative names for bubble productions with these features are bubble streams and whistle trails. The vast majority of articles use the terms bubble trail and bubble stream interchangeably, though there are a few articles in which these terms are characterized differently on the basis of structure (e.g., Dudzinski, 1996) or on physical features and behavioral use (e.g., McCowan et al., 2000). The term whistle trail (e.g., Pryor, 1990; van der Woude, 2009) is exclusively used to refer to bubble trails emitted concurrently with whistles, although the features of the bubble emission are structurally identical. This term occurs in the acoustic literature and, along with the term bubblestream whistle (e.g., Fripp, 2005), is used with respect to the practice of using bubble trails to identify the whistling individual in view.

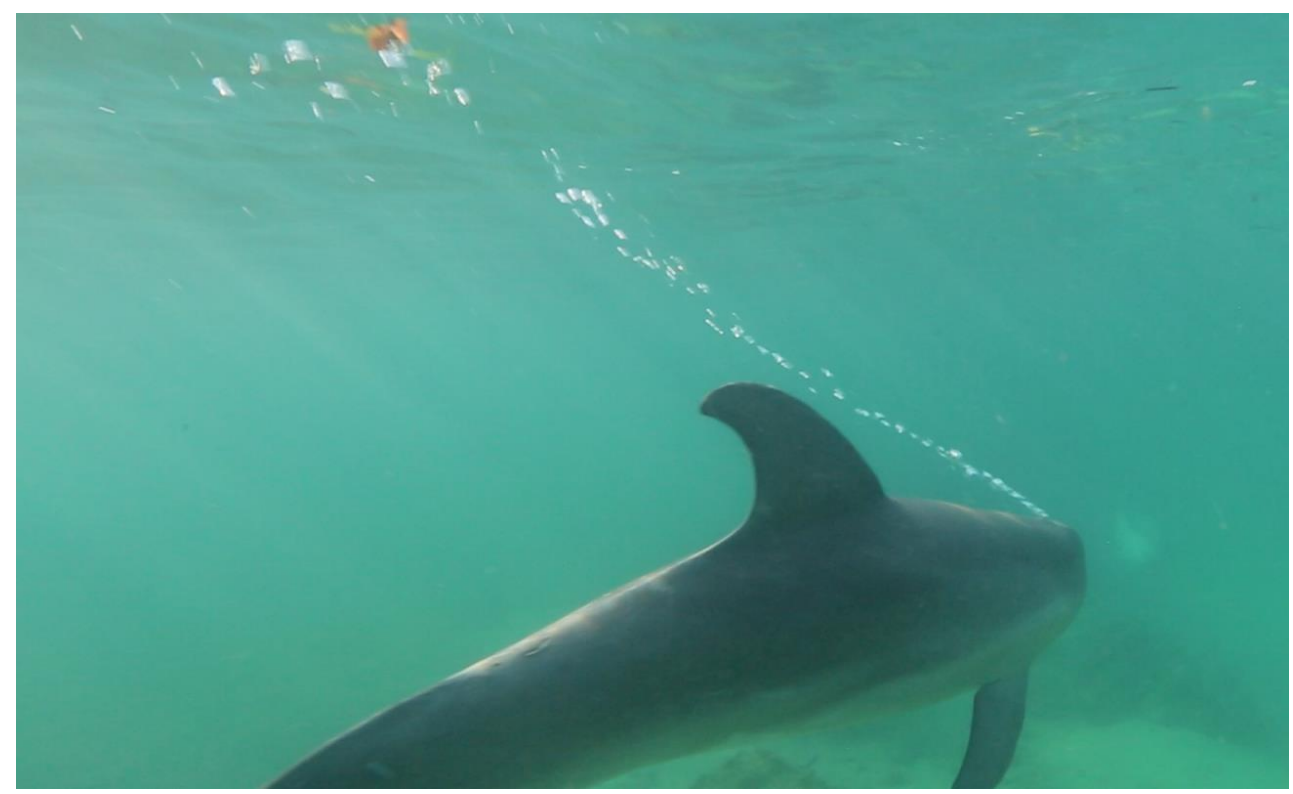

Figure 1. Bubble trail by an Atlantic bottlenose dolphin. Photo courtesy of Stan Kuczaj and the Roatan Institute for Marine Sciences.

Other, less common, terms are the bubble blow, bubble column, and bubble train. The first is used by Lusseau (2006) and is defined as "exhaling underwater, producing a stream of bubbles" (p. 263). The latter two were used by Trudelle (2010) to denote bubble trails differentiated by angle relative to the producing dolphin, with bubble columns in a vertical orientation and bubble trains in a horizontal orientation. However, this feature would be determined by a dolphin's movement, rather than the emission features of the bubbles, and therefore, both can be considered bubble trails.

\section{Proposed Behavioral Functions}

Bubble trails are predominantly observed in a variety of social situations (Beard, 2007; Dudzinski, 1996; Herzing, 1996; Pryor, 1990), and are connected to multiple other behaviors, including investigation, open mouth displays, surfacing, sexual behavior, human interaction (Moreno, 2017), and vocalizations (Ames et al., 2017; Fripp, 2005; Herzing, 1996; McCowan et al., 2000). They are also particularly common in groups with multiple individuals producing bubble trails (Beard, 2007; Moreno, 
2017). However, based on existing reports of bubble trail function that span multiple contexts, we have yet to decipher the information conveyed by this behavior. Current reports suggest a number of different hypotheses for how bubble trails are used. These include that bubble trails indicate stress, distress, or aversion, play a role in agonistic interactions, serve to maintain synchrony, work in conjunction with vocalizations for emphasis, modification of information, or visual indication of source, or are involuntary by-products of physiological processes, such as whistling in calves. Bubble trails are documented in multiple contexts and likely have multiple uses; thus, all of these hypotheses should be examined and should not considered mutually exclusive.

\section{Evidence for and Against Proposed Functions}

Stress, distress, and aversion. One proposed function of bubble trails is as an indicator of distress. Kuczaj et al. (2015) described underwater observations of a wild adult Atlantic bottlenose dolphin that appeared to be in distress letting out long continuous bubble trails and repeated whistles while sinking down in the water column. Bubble trails and whistles were also emitted by the dolphin while it was being assisted by other dolphins, and when it was able to swim to the surface. The authors concluded the bubble trails emitted during sinking bouts were most likely linked with the dolphin's whistles. However, they acknowledged the bubble trails could have been a result of her condition, a distress indicator, or an aid for visual communication toward the present conspecifics. Given the data available, it was not feasible to determine which of these possibilities was occurring.

Bubble trails have also been observed during other stressful events, including high-arousal social situations and proximity to aversive objects. An observational study found that spotted dolphins produced bubble trails in conjunction with a whistle-squawk-like "excitement vocalization" (Herzing, 1996, p. 66). The vocalization is described as a combination of a signature whistle and a burst pulse, and occurred in contexts that were considered to be distressing, leading the author to conclude the bubble trails were indicative of distress as well. In support of her interpretation, it was noted the contexts were triggered by intraspecific social interaction or human observer presence, and the dolphins exhibited highly erratic swimming behavior. Additionally, dolphins stopped this vocalization after receiving physical contact from another dolphin, which may indicate the individual "calmed down" (Herzing, 1996, p. 66; 2000, p. 273). The producers of these vocalizations and bubble trails were typically under three years of age (Herzing, 1996), indicating this use may be specific to immature individuals.

In another study, Commerson's dolphins (Cephalorhynchus commersonii) residing in managed care were presented with simulated fishing gear (i.e., a float or a gillnet stimulus paired with a novel acoustic net alarm [pinger]) to record their response to these objects. The pinger was considered aversive due to agonistic behaviors in the presence of it, avoidance of objects after the pinger was no longer present, and continuation of negative responses across trials. Dolphins produced bubble trails and bursts in conjunction with many high energy behaviors, including swimming rapidly, bowing, spinning while swimming, and chasing. These behaviors were performed either in synchrony with other individuals or independently (Bowles \& Anderson, 2012). All the behaviors seen in the presence of the aversive pinger were concluded to be those stemming from avoidance and aggression (Bowles \& Anderson, 2012), though they could have also been indicators of stress or distress.

Agonistic. A related hypothesis is that bubble trails serve as an agonistic signal. It is well supported that bubble trails are used in agonistic interaction, but the detail on how they are used during this context has yet to be established. It is possible these findings also support the previous hypothesis that bubble trails are produced during stress, distress, or aversion, as many conflict situations contain stressful, distressing or aversive instances. Most observations documenting bubble trail use during agonistic interactions have been in spotted dolphins. Dudzinski (1998) noted that bubble trails were often produced when swimming rapidly or during head-to-head orientation, in conjunction with increased vocal activity and other aggressive behaviors, including hitting, biting, raking, and open mouth displays. During bouts of chasing and hitting, dolphins combined bubble trail emissions with intense whistles (Dudzinski, 1998). Because fewer bubbles were produced during affiliative interactions than agonistic interactions, 
Dudzinski (1998) suggested that bubbles may indicate levels of excitement or agitation, or may be used as a shield to somewhat mask characteristics of an individual from its opponent in aggressive interactions. Bubble trails have also been observed synchronously with squawks/barks, vocalizations that have been produced by male spotted dolphins during aggressive behavior (Herzing, 1996). Wood (1953) also describes barks paired with bubble trails emitted by a spotted dolphin while being chased by a bottlenose dolphin under human care. Though the author speculates that the chase seemed to be "good natured" (p. 129), no evidence is provided in support of this, and chasing is more commonly considered to be an agonistic behavior. Another instance of this aggressive vocalization paired with bubble trails occurred when a tiger shark (Galeocerdo cuvier) was placed into the dolphins' enclosure. A spotted dolphin began continuously swimming past the shark from a distance and performing the squawk/bark with a bubble trail (Wood, 1953).

Other species in which bubble trails have been observed during agonistic situations include bottlenose dolphins and humpback whales. In bottlenose dolphins, bubble trails, termed bubble blows in this instance, were one of a number of behaviors that occurred more often during group orientation changes (Lusseau, 2006). Co-occurence of raspberries and chuffs, behaviors associated with aggression, suggests the bubble blows were aggressive in nature. The author speculates these behaviors together were indicative of conflict during decision making, though this was not directly tested. Additionally, the author used surface observations, and acknowledges that the findings on possible functions of certain behaviors may be different for studies utilizing underwater observations.

Humpback whale escorts have used bubble trails during intrasexual competition in the presence of a mother and her calf or with a lone female (Baker \& Herman, 1984; Tyack \& Whitehead, 1982). These occurrences were aggressive in nature, as primary escorts would temporarily leave the female to ward off intruding whales using physical contact, fluke thrashes, and head lunges. Bubble trails were used by the primary escort to form a temporary barrier between them and the potential secondary escort (Baker \& Herman, 1984; Tyack \& Whitehead, 1982).

Maintaining synchrony. Bubble trails are also hypothesized to facilitate synchrony during foraging in dusky dolphins (Lagenorhynchus obscurus; Trudelle, 2010) and orcas (Visser et al., 2008). In a study on dusky dolphin foraging, bubbles were not physically used to capture the prey; instead they were emitted most frequently before dolphins accelerated towards prey balls. Of those occurrences, there were descriptively (not significantly) more bubble trails than any other type emitted. The author suggests that bubbles may have functioned as a visual signal to initiate synchronization between conspecifics for more effective prey capture (Trudelle, 2010). There were also multiple instances of long-duration bubble trails produced when the focal dolphin swam away from the prey ball, further supporting a use other than a physical role in foraging. However, unlike the bubbles preceding approach of the prey ball, no alternative function was proposed for these bubble emissions (Trudelle, 2010).

Bubble trails have also been observed during synchronous foraging behaviors in orcas. Visser et al. (2008) observed a group of orcas attempting to knock a seal off an ice float. During this instance, four individuals produced bubble trails as they accelerated in synchrony just beneath the ice float, creating a large wave that subsequently washed the seal into the water. The authors suggested the bubble trails may have been accompanied by vocalizations due to findings linking these behaviors in bottlenose dolphins, but provide no other support for this conclusion. Similar to findings for dusky dolphins, these bubble trails may have been used to communicate coordination between individuals.

Supplementing vocalizations. The term whistle trail is indicative of the common association between bubble trails and whistles. This link is primarily due to current methodology that relies on bubble trails to isolate whistles and identify which individual is vocalizing (Ames, 2016; Herzing, 2000; McBride \& Kritzler, 1951). This is particularly useful when assessing the vocal repertoire of young calves because their whistle and bubble trail productions are strongly associated (Fripp, 2005; Gnone \& Moriconi, 2009; McCowan \& Reiss, 1995, 2001; Morisaka, Shinohara, \& Taki, 2005). It is currently accepted that adult cetaceans have the necessary motor control over the release of air from the respiratory system and immature individuals have less control over maintaining a sealed blowhole when performing actions in the air passages, such as whistling (Gnone et al., 1996; McCowan, 2006; McCowan \& Reiss, 
1995). An association between bubble release and whistling has been found for the first month of life in bottlenose dolphins (Gnone et al., 1996); however, we do not know at what age respiratory control matures to the point where bubbles are no longer a byproduct of whistling. Unfortunately, we are still poorly informed on this mechanism and its development.

For adults, presence of a bubble trail concurrent with a whistle is a useful tool for determining which individual vocalized (McCowan, 2006; McCowan \& Reiss, 1995). However, relying solely on whistles accompanied by bubble trails can bias findings, particularly given the evidence that they are not physiologically linked and that bubble production plays a behavioral role, both in conjunction with whistles and on its own. Vocalizations are made through vibrations of internal air sacs and do not require the release of air from the blowhole (Mackay \& Liaw, 1981), and bubble productions do not require the presence of vocalization. Because bubble trails and whistles are often observed with one another, it is likely they are signals of different modalities working together. This is supported by evidence of bubble trails and whistles co-occurring most frequently in particular contexts, such as during labor, when the environment suddenly changes (e.g., introduction of a new calf), when a calf is present, and during mother-calf separation (Fripp, 2005). Additionally, bubble trails frequently occur in temporal clusters and are not associated with all whistle types (Fripp, 2005, 2006). However, the precise function of the relationship of bubble trails to whistle types, behavioral states, and affective states is currently unclear, and more research is needed in this area (Fripp, 2005, 2006; McCowan, 2006; McCowan \& Reiss, 1995).

Bubble trails have also been reported in conjunction with non-whistle vocalizations and likely serve to supplement, modify, or draw attention to vocal information. In bottlenose dolphins, a study of thunk vocalizations during separation events found bubble trails in over $40 \%$ of events (Ames et al., 2017). The authors propose the bubble trails were used as an identification display, and suggest this function be investigated through future research. Bubble trails have been observed in conjunction with whistle-squawks and barks in spotted dolphins, which are associated with distress and aggressive behavior, as detailed above (Herzing, 1996, 2000; Wood, 1953). In orcas, bubble trails have been demonstrated to be disproportionately associated with biphonic calls that had a divergent high frequency component (DHFC; Bowles, Grebner, Musser, Nash, \& Crance, 2015) and were not concurrent with another synchronous behavior, nodding, that was associated with a different call type (Bowles, Musser, Clark, Denes, \& Grebner, 2016). As this call type is thought to have a role in group cohesion, bonding, maintaining social stability, and group action, the authors concluded the visual characteristics of bubble trails are likely used to either draw attention to the call (Bowles et al., 2015) or modify the information conveyed by the calls (Bowles et al., 2016).

The relationship of bubble trails with whistles (Herzing, 1996; Pryor, 1990) and other vocalizations (Ames et al., 2017; Bowles et al., 2015; van der Woude, 2009; Wood, 1953) indicates a tandem function for dolphins, perhaps for emphasis, source localization, or information modification (Ames et al., 2017; Bowles et al., 2015; Pryor, 1990). If these proposed functions are correct, it would clearly demonstrate the use of bubble trails as visual signals. A better understanding of bubble trail use, particularly with respect to vocal production, would also provide further insight into multimodal communication.

\section{Species Differences}

There may be differences in frequency or function of bubble trails between and within species. This could be due to inherent differences in bubble function itself, or differences in features that precipitate bubble production, such as how easily excitable or agitated the species tends to be. During observations of spinner dolphins (Stenella longirostris) and Pacific spotted dolphins (Stenella attenuata) contained in a purse seine net, it was reported that spinner dolphins whistled and emitted bubble trails more often than spotted dolphins (Pryor \& Kang, 1980). Also, in experimental trials assessing behavioral responses to expectation-violating stimuli, rough-toothed dolphins (Steno bredanensis) were found to produce more bubble trails per trial than bottlenose dolphins (Lilley, de Vere, Yeater, \& Kuczj, 2018). 


\section{Demographic Differences}

Demographic differences in the frequency of bubble trail production are evident. One study found female bottlenose dolphins produced more bubble trails than males (Beard, 2007). This may be related to the finding that bubble trails were produced the most by individuals who were in the presence of a calf (Beard, 2007), because females and calves are typically in proximity to each other more often than males and calves are (Mann \& Smuts, 1999; Wells, Scott, \& Irvine, 1987). Between age-classes, subadults were found to produce the most bubble trails, followed by juveniles, and then adults. Calves produced the least amount of bubble trails (Beard, 2007). A separate study found that individuals were more likely to be bubble producers if they were not calves ( 11 individuals birth to 4 years of age, 20 individuals 5 years of age and above; Moreno, 2017). This is particularly interesting because it contradicts what we expect to see given reports that calves produce bubble trails involuntarily when whistling (Gnone et al., 1996; McCowan, 2006; McCowan \& Reiss, 1995). If calves are unable to suppress bubble release while whistling, we would expect calves to produce more bubble trails than dolphins of older age-classes, who should have more control over bubble release. This apparent discrepancy may be due to how these studies defined age groups. Although we do not know the age at which muscular control is sufficiently developed to prevent bubble trail release as a side effect of whistling, current evidence for involuntary whistle production by calves focuses on neonates under one year of age. Thus, grouping neonates with older calves likely obscured the effect of physiological maturation. In beluga whales (Delphinapterus leucas), it was found that males produced the bubble trails more frequently than females, regardless of age-class (George \& Noonan, 2016).

\section{Future Directions}

Previous research has generated clear questions to focus upcoming research. As bubble trails are observed in multiple contexts, it will be valuable to determine if their use is stable across contexts, or is flexible and differs between contexts. One example of a function that could be utilized in several contexts is as an indicator of stress, which is supported by current findings (Bowles \& Anderson, 2012; Fripp, 2005; Herzing, 1996, 2000; Kuczaj et al., 2015). Other observations include uses in contexts, such as aggression, that may or may not be related to stress indication. Direct physiological measures would be the most effective way to demonstrate stress, though methods to measure such indicators in real time on free-ranging animals have yet to be developed.

Future studies of bubble trails, and other bubble types, should look into utilization of concurrent behaviors to determine if bubbles are a response to, or elicit a response from, another individual (e.g., Moreno, 2017). Also, a future study should compare behaviors during bubble production to times without bubble presence. Studies such as these would help us gain a better understanding of their general function across situations.

Bubble trails may also function in conjunction with other signals, like vocalizations, for purposes such as providing emphasis, gaining attention, identifying the signaler, or modifying information. For example, bubble trails alone seemed to signal synchrony before dolphins approached prey during foraging; however, this could not fully be determined by the study (Trudelle, 2010). An examination of signaling behaviors immediately preceding synchrony will be useful in making this distinction.

Multiple findings of a relationship between bubble trails and vocalizations indicates bubble trail research will need to incorporate vocal information rather than focus only on bubble trails in isolation. This will help us gain a complete picture of the behavior's function and untangle the relationship between bubble trails and vocalizations, and whistles in particular. One much-needed study would involve measuring all occurrences of whistles and all occurrences of bubble trails within a given sampling period or under controlled conditions. Despite being methodologically difficult due to the need for an alternative mechanism for identifying vocalizers, such as a hydrophone array, a study like this would provide an invaluable comparison between whistles without bubble trails, bubble trails without whistles, and whistles with bubble trails. 
Lastly, more comparisons between demographic groups and species are also important to determine if bubble trails are a universal signal used by cetaceans. There is evidence of different frequencies of use between species (Lilley et al., 2018; Pryor \& Kang, 1980); current evidence suggests their function differs as well. Furthermore, differences in production between age groups indicates future studies should take age into account when reporting bubble trail behaviors. It would also be worthwhile to determine whether there are developmental changes in bubble trail function connected to maturation in physiological control of airways.

\section{Bubble Bursts}

\section{Terminology}

Another common form of bubble production is the sudden release of a large amount of air resulting in a cloud-like clustering of bubbles (Figure 2). Various sources commonly refer to this as either the bubble burst or bubble cloud, and the choice of which term is used appears to be due to author preference, though they can also be used interchangeably as in Dudzinski (1996). One exception to this is McCowan et al. (2000), in which the terms are used to denote separate categories defined on the basis of social context rather than bubble features. The authors describe the physical features of both as "a large number of small bubbles simultaneously released" (p. 100), specifying that bursts occur in surprise or fright contexts but clouds occur during aggressive interactions, particularly those including chases (McCowan et al., 2000). Defining bubble types by behavioral context rather than physical features has drawbacks, including difficulty ensuring terms are used consistently throughout the scientific community and confounding studies attempting to understand the function of those behaviors.

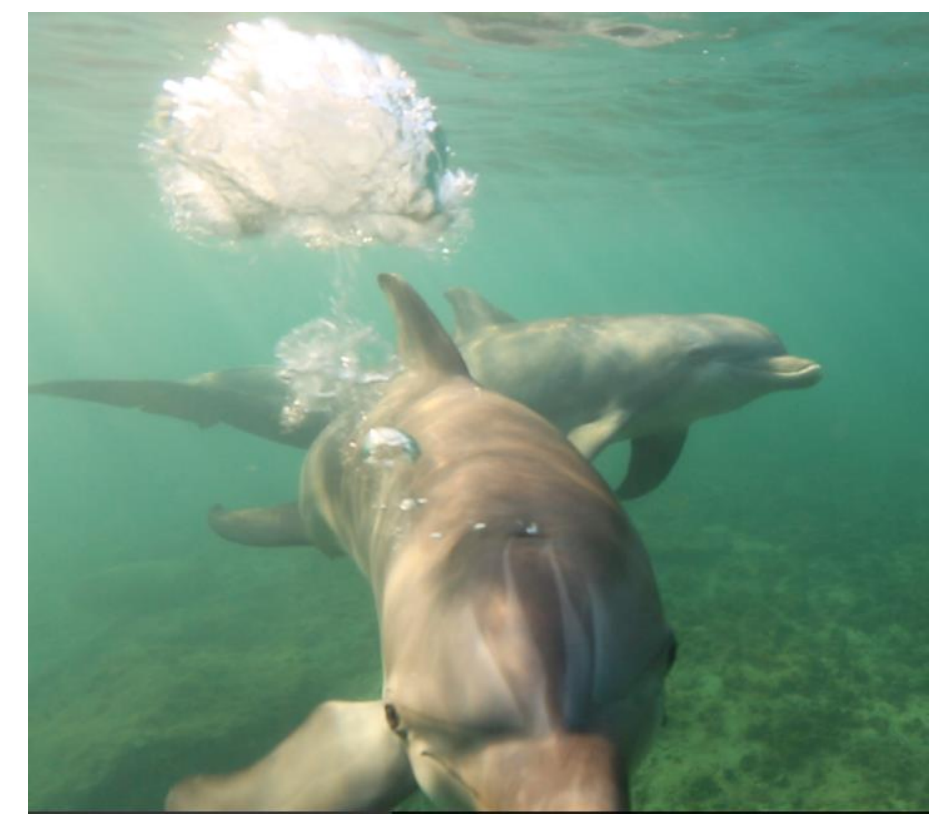

Figure 2. Bubble Burst by an Atlantic bottlenose dolphin. Photo courtesy of Stan Kuczaj and the Roatan Institute for Marine Sciences.

In addition to the common terms for bubble bursts, an older article used the term underwater blowing (Baker \& Herman, 1984). The behavior is described as the release of large bursts of air, once or in a sequence, and matches the operational definition for bubble bursts. Helweg, Bauer, and Herman (1992) also used the term underwater blow, which likely refers to a bubble burst because it references the Baker and Herman (1984) article, though no explicit description is provided. 


\section{Proposed Behavioral Functions}

A range of studies has reported bubble bursts, but knowledge of their function is limited. There are two commonly accepted functions of bubble bursts. The first is a threat or other aggressive signal (Baker \& Herman, 1984; Bowles \& Anderson, 2012; Dudzinski, 1996; Helweg et al., 1992; Herzing, 1996; Hill et al., 2011; McCowan et al., 2000), and the second is a response to a surprising, aversive, or interesting stimulus (Delfour \& Marten, 2001; Lilley et al., 2018; Marten et al., 1996; McCowan et al., 2000; Moreno, 2017; Pryor, 1990). Both conclusions are primarily supported by anecdotal data. It is important to note that these uses are not necessarily mutually exclusive because they have some behavioral overlap. For example, some individuals respond to surprising or startling stimuli with aggression or threat toward the stimuli. The reverse may also occur; individuals could startle from instances of aggression or conflict from conspecifics. Reactions of surprise can also be positive, such as with interest or curiosity, which is typically considered to be a beneficial experience rather than a negative one. Alternatively, bubble bursts may serve multiple functions. It is currently unknown whether bubble burst production is voluntary. Therefore, bubble bursts may be actively produced signals, reflexive responses to a situation, or a combination of the two that varies by context.

\section{Evidence for and Against Proposed Functions}

Agonistic. One proposed use of bubble bursts is as a threat or other aggressive signal. Support for this interpretation comes from observations in both human care and the wild. Commerson's dolphins and bottlenose dolphins released bubble bursts in conjunction with high energy and agonistic behaviors in response to simulated fishing gear and pingers. Based on the situation and the concurrent behaviors, the authors propose the bubble bursts were aggressive in nature (Bowles \& Anderson, 2012), though the behaviors could have also indicated distress. Similarly, spotted dolphins observed in the wild have been documented using bubble bursts in conjunction with aggressive behaviors (Dudzinski, 1996).

Observational research on belugas found that mothers produce significantly more bubble bursts in social interactions involving their calves and contexts in which a startle response occurred. In particular, this included situations such as another individual approaching the mother-calf pair or the calf moving away, leading the authors to conclude these bursts were used as a protective display or threat in defense of their calves (Hill et al., 2011). Possible explanations of the function of bubble bursts during aggressive situations are that they are used to diffuse energy, appear bigger, or provide camouflage due to their large size (Dudzinski, 1996).

Bubble bursts are also involved in specific types of aggressive contexts, such as intrasexual competition during mating. Humpback whales use bubble bursts in conjunction with other aggressive behaviors such as head lunges, tail thrashes, and s-postures during direct competition between escorts for access to a female (Baker \& Herman, 1984; Helweg et al., 1992). Like humpback whales, spotted dolphins (Herzing, 1996) and bottlenose dolphins (Moreno, 2017) use bubble bursts during sexual behavior. However, bursts in bottlenose dolphins are not accompanied by aggression (Moreno, 2017), and bursts in spotted dolphins are primarily produced by young adult males who were often unsuccessful in regards to copulation, which led to aggressive behavior (Herzing, 1996). Due to this association, Herzing (1996) suggests bubble bursts in these cases may have been more closely connected to the aggressive behaviors than the sexual behaviors, though a definitive conclusion could not be reached from the data available.

It is important to note that even though many reported instances of bubble bursts have occurred during contexts of conflict or aggression, such contexts do not automatically include bubble burst behavior. In a study examining the usage of agonistic s-posture displays in belugas, the authors did not observe bubble bursts, despite predicting these and other visual displays would co-occur with s-postures (Horback, Friedman, \& Johnson, 2010). Considering that s-postures and bubble bursts are both possible visual signals, the use of both could carry redundant information. Alternatively, the two visual displays may convey different information and could be used in different instances, similar to orcas' use of 
different visual signals in conjunction with different call types (Bowles et al., 2016). However, as other studies have found co-occurrence of multiple visual displays during aggression (e.g., Dudzinski, 1998; Overstrom, 1983), including bubble bursts and s-postures (Helweg et al., 1992), the relationship of multiple visual displays to one another is complex and poorly understood.

Surprise, excitement, interest, or curiosity. The other common interpretation of the bubble burst is as an indicator of surprise, excitement, interest, or curiosity. These exact terms are used by Marten, Shariff, Psarakos, \& White (1996) and McCowan et al. (2000) to describe the internal state of dolphins producing a bubble burst. Pryor (1990) focuses more on the surprise aspect and states the bubble burst is typically produced by individuals presented with an unfamiliar stimulus, such as a noise or a visual. She dubs the behavior a "query balloon" (p. 540), to reflect this focus, capturing both the physical form and interpreted function in the whimsical term. Unfortunately, these sources do not demonstrate support for their conclusions, nor do they cite where the interpretations came from.

There are currently few studies that use behavioral evidence to demonstrate bubble bursts are indicative of surprise, curiosity, interest, or excitement. One study compared behavior between bubble producers and non-producers before, during, and after bubble production in bottlenose dolphins (Moreno, 2017). Bubble burst producers were more likely to engage in object manipulation, open mouth, and human interaction behaviors, which the author interprets as indicative of high levels of interest and engagement (Moreno, 2017). Another study found beluga mothers produced more bubble bursts than expected by chance in contexts involving a startle response (Hill et al., 2011). Only one study so far has demonstrated differences in bubble burst production in response to presented stimuli. In testing the responses of bottlenose and rough-toothed dolphins to two situations designed to elicit curiosity, Lilley et al. (2018) found more bubble bursts in response to a spontaneously moving stimulus than the non-moving control. Additionally, when presented with either expectation-violating or expectation-confirming object transformations, the dolphins produced numerous bubble bursts. The authors note this could be due to features that were not manipulated across trials, such as general interest, a response to the objects themselves, or communication to other dolphins in the area.

\section{Demographic Differences}

Two studies have compared differences in bubble burst production between sexes, with differing results. Moreno (2017) found sex did not predict whether an individual was the producer of a focal bubble burst in an analysis of 122 events produced across 31 (16 male, 15 female) bottlenose dolphins. In contrast, Lilley et al. (2018) found greater production rates in females than males in bottlenose (six males, nine females) and rough-toothed (three males, three females) dolphins.

There is evidence suggesting bubble burst use may differ by age. In an observational study on beluga bubble burst production ( 814 bubble bursts) in four mother-calf pairs, calves primarily produced bubble bursts when alone or during social interactions. Their mothers primarily produced bubble bursts in social interactions involving their calves, during pair swims with their calves, and contexts in which a startle response occurred (Hill et al., 2011). George and Noonan (2016) found that adult female belugas produced bubble bursts at a higher rate per minute, but the reverse was true for juveniles, with males producing more of this bubble type per minute.

\section{Large Single Bubble}

There are reports of an additional bubble type that is produced by exhaling a large amount of air in a single instance, similar to the bubble burst. This type takes the form of a large, singular bubble, which may be a bubble burst that is poorly described or not seen clearly, a subcategory of the bubble burst, or a distinct category of its own. It has yet to be named despite appearing in a handful of publications. The oldest report of this bubble type is the inclusion of the behavior "big underwater bubble" (p. 262), in the category of behaviors considered to play a role in aggression (Shane, 1990). It is defined as a singular large bubble with a diameter over $10 \mathrm{~cm}$. Unfortunately, we lack information on how this bubble type was 
used, as it was not incorporated into the final analysis and no additional information on concurrent behaviors or why it was considered an aggressive behavior was provided. The next instance of singular bubbles does not include a size description but provides a detailed account of an occurrence in which these bubbles were observed. The instance involves a group of spotted dolphins that alternate between aggressive bouts, characterized by fast swimming, head to head posturing, hitting, biting, and other injurious behaviors, and affiliative bouts, characterized by swimming in synchrony, body contact, and pectoral fin contact. The singular bubbles, along with bubble trails and bubble streams (which the author operationally defines as different bubble types, see bubble trail terminology), occurred during the aggressive bouts, particularly during fast swimming and head-to-head orientation (Dudzinski, 1996, 1998).

In contrast to the above reports are three findings of singular large bubbles outside of an aggressive context. In a study of bubble ring play in bottlenose dolphins large, single bubble productions occurred in a similar frequency to bubble rings (McCowan et al., 2000). They were often manipulated similarly to the bubble rings, suggesting the possibility they were failed attempts at making bubble rings or were lower effort toys. More recently, a study that presented an underwater maze device to dolphins for cognitive enrichment found bubble production to be one of the behavioral responses to the device (Clark, Davies, Madigan, Warner, \& Kuczaj, 2013). Specifically, the bubbles observed were described as a large spherical bubble produced by forcefully expelling air from the blowhole. The bubbles were clearly produced in response to the device, as none were recorded during baseline observations when the device was not present, $29 \%$ of the recorded bubbles were produced while in contact with device, $32 \%$ were produced while looking at the device, $36 \%$ were produced while watching another dolphin interact with the device, and 3\% were produced while the experimenter was submerging the whole device or a ball into the device. Single bubbles have also been noted in dusky dolphins during a foraging context, though no details beyond an occurrence count were provided (Trudelle, 2010).

The large singular bubbles described above exhibit a number of similarities to the bubble burst, including their size and behavioral function. Both bubble bursts and large singular bubbles are generated by the quick exhalation of a large quantity of air. The difference is the former tends to break apart or be composed of multiple air pockets together but the latter is a single sphere. Due to these slightly different features, the manner in which the air is released could not be identical. Supporting this difference in features are two studies that report single large bubbles and bubble bursts as distinct bubble production categories and provide different operational definitions for each (Dudzinski, 1996; McCowan et al., 2000). The function of bubble bursts and single large bubbles bears far more similarity than their form. Of the five reports, two link the bubble type to aggression (Dudzinski, 1996; Shane, 1990) and one links it to interest and surprise (Clark et al., 2013), functions that are widely accepted for the bubble burst.

\section{Evolutionary Origins}

There is evidence the bubble burst may be derived from a common Artiodactyla behavioral response called a snort (D. Reiss, personal communication, December 12, 2015). This behavior consists of a short, forceful exhalation of a large amount of air, which, if produced underwater, would take the form of a bubble burst. Snorts, and similar forceful exhalation blows, are common behaviors among a range of Artiodactyla species, indicating it is likely phylogenetically retained or a reversal to an ancestral characteristic (Cap, Deleporte, Joachim, \& Reby, 2008; Kiley, 1972). It is commonly accepted that Cetacea falls within Artiodactyla (Boisserie, Fisher, Lihoreau, \& Weston, 2011; Graur \& Higgins, 1994; O'Leary \& Gatesy, 2008), and thus, a comparison is useful for understanding evolutionary behavioral development.

Deer, a large family within Artiodactyla, use snorts for a range of functions and situations. One primary category of snort use in deer is during conflict; Cervus nippon, Moschus moschiferus, and Odocoileini species use snorts during intraspecific competition (Atkeson, Marchinton, \& Miller, 1988; Richardson, Jacobson, Muncy, \& Perkins, 1983). For example, C. nippon snorts during territory defense, and typically in conjunction with non-herding mating calls (Cap et al., 2008). Similarly, Odocoileini sp. 
pair their snorts with other vocalizations, such as grunts and wheezes to modify the meaning of their vocalizations (Richardson et al., 1983). The other primary function of snorts in deer is as an alarm signal. In Odocoileini and Rangifer species of deer, the snort serves as a predator deterrent signal, replacing the bark vocalization used by other species for this purpose (Cap et al., 2008). Additionally, giraffes, another Artiodactyla group, use snorts in response to a possible threat (Volodina, Volodin, Chelysheva, \& Frey, 2018).

Like Artiodactyla, members of its sister clade Perissodactyla use snorts in aggressive and alarm contexts. Tapirs, rhinos, zebras, and donkeys commonly snort when alarmed (Kiley, 1972), and tapirs also use snorts in aggressive contexts (Kiley, 1972). Horses snort when investigating a strange object (Kiley, 1972) or when they are fearful, although this is not a true alarm signal (Leiner \& Fendt, 2011). All of the functions for snort behavior bear similarity to the proposed functions of bubble bursts, further supporting the homology of these two behaviors.

In addition to Artiodactyla and Perissodactyla species, there are a few reports of other mammals using snorts. For example, male polar bears utilize snorts during intrasexual competition (Frankel, 2018), male ringed seals direct snorts at adult females as a courtship behavior (Mizuguchi, Tsunokawa, Kawamoto, \& Kohshima, 2016), and foxes (Gogoleva, Volodin, Volodina, Kharlamova, \& Trut, 2010; Tembrock, 1976), Guinea pigs (Morton, 1977), and elephants (Stoeger-Horwath, Stoeger, Schwammer, \& Kratochvil, 2007) all use a snort vocalization in a manner considered aggressive.

\section{Future Directions}

Bubble bursts have been described through many anecdotal accounts to function in a variety of situations as a response behavior. Due to this, future research should aim to develop empirical studies based on the hypothesis that the use of bubble bursts is as a response due to startle, aggression, surprise, excitement, interest, and/or curiosity. Following Lilley et al. (2018), studies that measure bubble production responses to introduced stimuli that differ in a single feature likely to elicit a bubble burst will help us better understand when bursts are used.

Differences in use across demographic categories are poorly understood. There is already evidence that beluga mothers and calves use bubble bursts differently, though we do not know how this behavior compares to other members of the population. Additionally, there is conflicting evidence regarding sex differences in bubble burst production. This indicates a need for further comparison between age and sex categories.

Our understanding of the behavioral use of bubble burst will benefit from determining whether it is voluntary, involuntary, or some mixture of both. One possibility for studying bubble burst production control would rely on training dolphins to produce bubble bursts on command. Bubble bursts produced on request should involve a delay due to cognitive processing. Comparing this reaction time with the reaction time for bubble bursts produced when presented with a surprising stimulus, similar to stimuli used in Lilley et al. (2018), could demonstrate whether bubbles in response to a surprising stimulus involve a delay attributed to cognitive processing or are reflexive.

Given the phylogenetic and behavioral evidence for bubble bursts as a behavior derived from the general mammalian snort, further research into the evolutionary history of these behaviors is warranted. One possible direction of research is better understanding when the snort behavior was first developed and which species retain it. This could be achieved through mapping the snort onto a phylogenetic tree (such as social displays in pelecaniform taxa; Kennedy, Spencer, \& Gray, 1996), though we will first need more reports on which animals do or do not use the behavior.

Another direction would be to focus on the evolution of the bubble burst in cetaceans specifically. Retention of this ancestral behavior in a dramatically different environment relies on either low selective pressure against the behavior, high benefit of the behavior, or both. Given the visibly large air volume released, there appears to be a cost to respiratory resources accompanying this behavior. Physiological studies could determine what proportion of air is lost through bubble burst production by comparing lung capacity to bubble burst volume. Despite not being a direct measure of physiological strain, such 
information would shed light on whether a selective pressure against the behavior exists. To assess the benefit of the behavior, studies on the fitness impacts of the behavior, such as whether bubble burst signaling of potential threats reduces mortality, or whether a correlation exists between bubble burst production and male competitive or reproductive success would be highly beneficial. Studying how bubble bursts are used in sexual contexts, such as courtship and intrasexual competition, could provide insight into the fitness impacts as well.

\section{Bubble Rings}

\section{Terminology}

The third commonly reported type of bubble production is the bubble ring, a release of air that forms a single, unbroken torus (Figure 3). Due to the unambiguous nature of its shape, the literature on this bubble type is consistent in both description and naming. In addition to bubbles produced through exhalation, bubble rings can also be produced by physical means, such as by fluke slaps (Pace, 2000), or release of air trapped in the mouth (Gewalt, 1989).
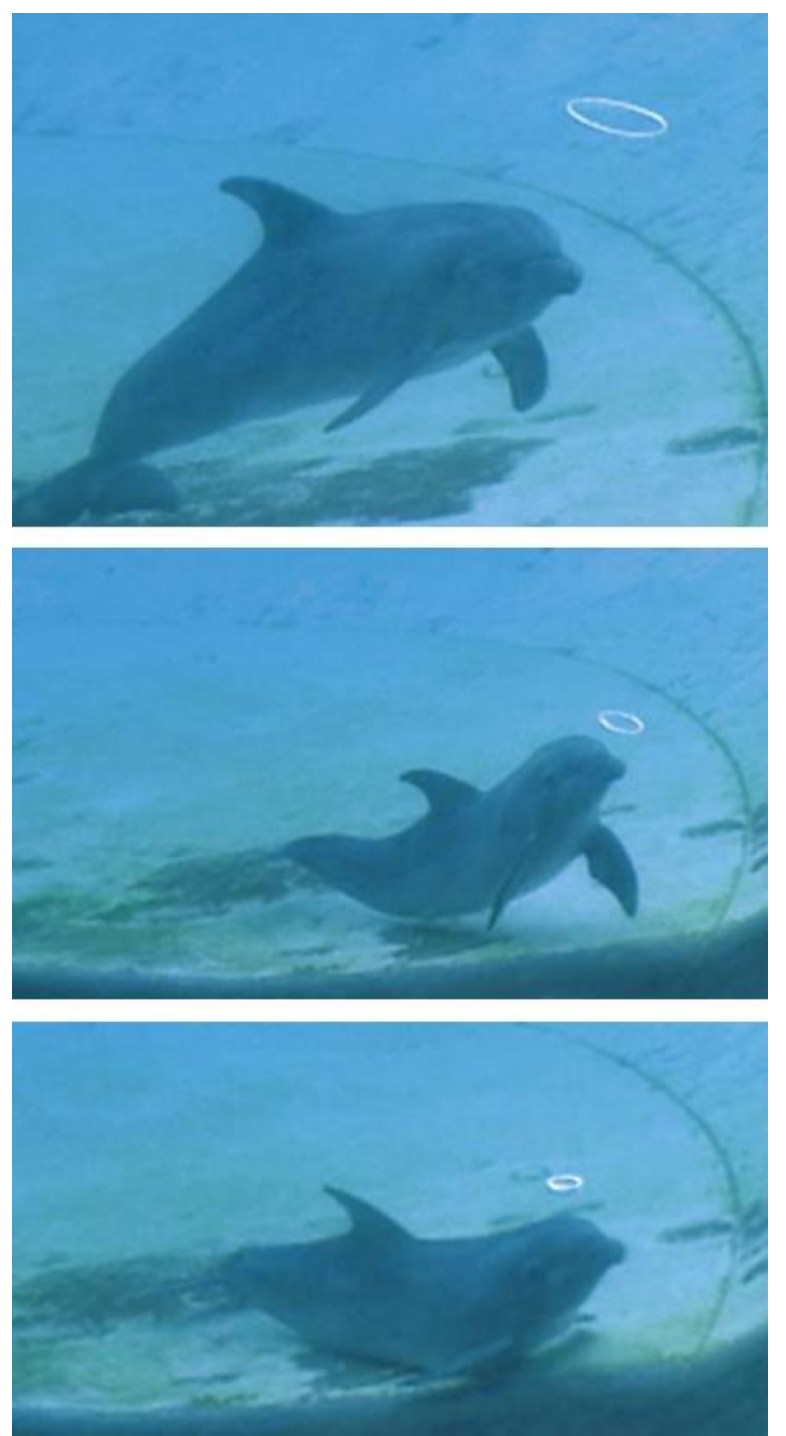

Figure 3. Bubble Ring by an Atlantic bottlenose dolphin. Photo courtesy of Ken Marten, Suchi Psarakos, and Don J. White, Earthtrust. 


\section{Proposed Behavioral Functions}

Bubble rings are observed far less often compared to the other bubble production types. They seem to mainly serve as manipulable objects utilized during play. However, outside of this, bubble rings may also function as a signal of aggression, dominance, or annoyance during conflict.

\section{Evidence for and Against Proposed Functions}

Play. Unlike bubble trails and bursts, rings are commonly discussed in association with play behaviors, and most reports are of cetaceans producing and then manipulating the rings (Gewalt, 1989; Marten et al., 1996; McCowan et al., 2000; Pace, 2000; Paulos et al., 2010). Bubble ring play has been observed in multiple species, including belugas (Hill, 2009), Orinoco dolphins (Inia geoffrensis; Gewalt, 1989), and bottlenose dolphins (Marten et al., 1996; McCowan et al., 2000; Paulos et al., 2010). Though these examples are intriguing, it is important to note that bubble play is not a common form of play, and is generally observed in managed, not wild, populations (Paulos et al., 2010). This is likely due to researchers having direct access and better visibility to more easily observe the behavior of individuals residing in managed care compared to the wild. Although bubble ring play has not been documented in the wild, this does not mean there is no possibility it could occur. Several reports of bubble ring production by dolphins residing in managed care described the dolphins assuming distinctive postures in a particular area of their enclosure in the water column before producing them (Marten et al., 1996; McCowan et al., 2000). It was thus suggested that "production of stable rings may require some practice, expertise, and forethought" (McCowan et al., 2000, p. 98).

Agonistic. Despite the prevalence of reports on bubble ring play, not all bubble ring productions are used in this manner. Observations of non-play bubble rings suggest they are related to conflict. Bubble rings have been observed in spotted dolphins concurrently with burst pulse vocalizations such as squawks, barks, and screams, and behaviors commonly considered to be aggressive, such as head-to-head displays, open mouth postures, body charges, and tail slaps to the head, particularly between males (Herzing, 1996, 2000). Similarly, other sources note the presence of bubble rings during dominance disputes between spotted dolphins within a purse seine net (Pryor, 1990; Pryor \& Kang, 1980), or contexts labeled as annoyance (Herzing, 2000)

\section{Demographic Differences}

Reports of bubble ring play do not indicate differences in prevalence of these productions by sex, nor age. Although play is an important component of the behavioral repertoire for all age groups (Hill, Dietrich, \& Cappiello, 2017), younger bottlenose and spotted dolphins tend to engage in object play more often than older dolphins (Cappiello, Hill, \& Bolton, 2018; Greene, Melillo-Sweeting, \& Dudzinski, 2011). It has been noted that bubble ring production takes time to perfect and seems to be aided by social learning (Kuczaj, Makecha, Trone, Paulos, \& Ramos, 2006; Marten et al., 1996; McCowan et al., 2000).

Observations of bubble rings in non-play contexts have been documented only for spotted dolphins (Herzing, 1996; Pryor \& Kang, 1980). Both studies note that males produce bubble rings during agonistic interactions but do not mention whether males produce more than, or the same amount as females. Additionally, the ages of males producing rings during conflict are not indicated.

\section{Future Directions}

Future research focusing on bubble ring behavior could help further explain the use of this bubble type outside of play. Due to the motor control needed to produce rings, we expect their production is intentional and they serve a distinct purpose, though this purpose remains to be identified. Current findings suggest bubble ring production may sometimes be involved in agonistic situations; however, all three of the well-established bubble types that we have discussed (bubble trails, bubble bursts, and bubble 
rings) have been observed in aggressive contexts. This brings up the question of whether there are differences between the use of each bubble production type during aggressive interactions, or if they are interchangeable. To answer this, research focusing on bubble use during conflict is needed. Such studies should focus on differences and similarities between bubble types, such as comparisons in behavioral differences, demographic or species differences, type of aggressive interaction, and the role the bubble producer plays in the conflict.

\section{Other Bubbles}

\section{Scant Bubble or Blowhole Drip}

In addition to bubble trails, bubble bursts, and bubble rings, there are reports of bubbles that do not match the features of one of these categories. One bubble type that is clearly defined and does not fit into the well-established categories is called the scant bubble or blowhole drip. This type also contains a minimal number of bubbles, but it is distinct from the singular large bubble in terms of size. Our knowledge of this type comes from two reports, one of which defines it as bubbles that are "small, sparse, and few" (Moreno, 2017, p. 12; Figure 4).

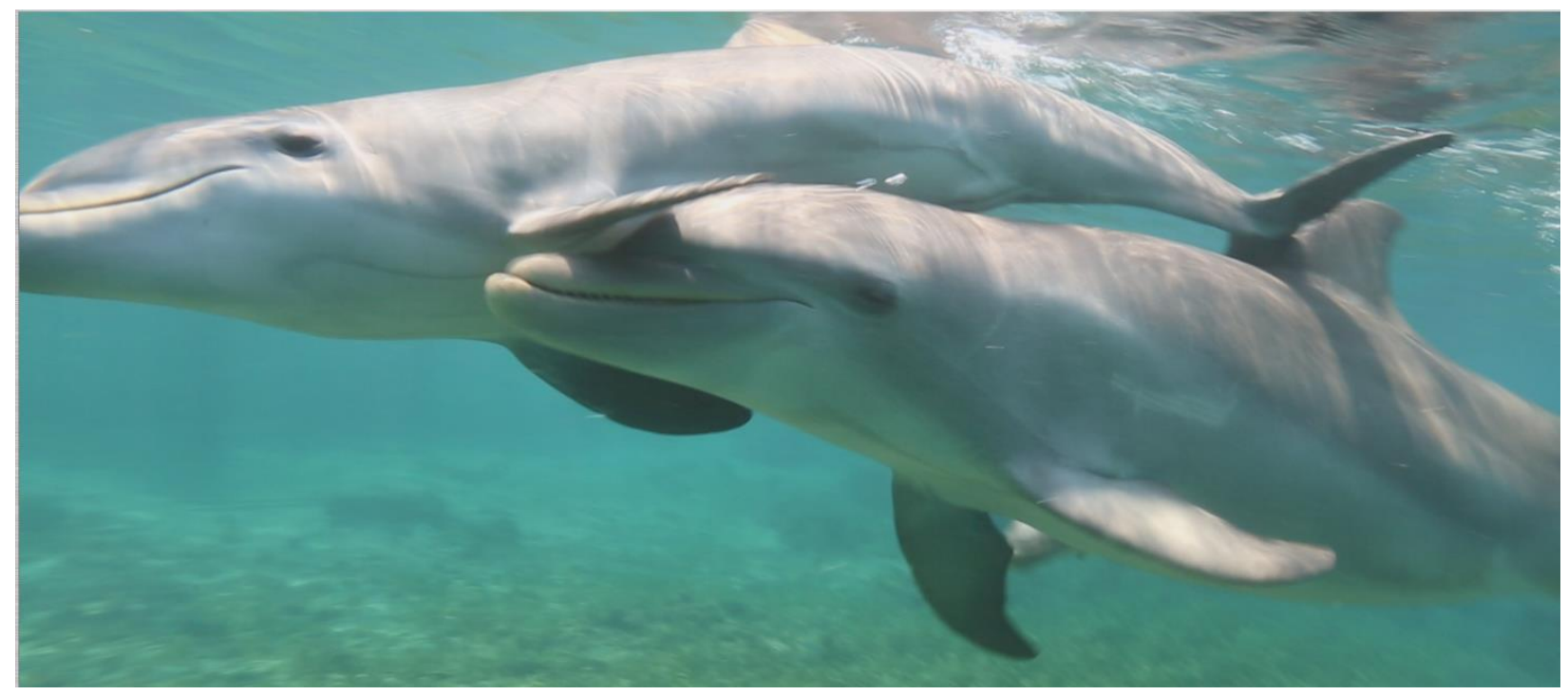

Figure 4. Scant bubble by an Atlantic bottlenose dolphin. Photo courtesy of Stan Kuczaj and the Roatan Institute for Marine Sciences.

Using other behaviors to predict whether an individual produced a scant bubble or was present during scant bubble production, this bubble type was found to be associated with synchronous swimming, contact, object manipulation, surfacing, production of other bubble types, open mouth, and human interaction. This led the author to conclude they are used in close proximity social interactions, as a response during object investigation, and are not associated with aggression or avoidance (Moreno, 2017). Due to methodological limitations, vocalizations were not included in the study; whether there is a relationship between scant bubbles and vocal behavior remains to be determined. Like other bubble types, it is unknown whether scant bubble production is voluntary.

Very similar, and possibly identical, to the scant bubble Moreno (2017) described is a bubble type observed in beluga whales termed a blowhole drip (George \& Noonan, 2016; Figure 5). It was found that females produce more of this bubble type than males, and juveniles produce more than adults. In an article on ScienceDaily.com, research by Dr. Noonan and Ms. George suggest that along with bubble rings, drips may indicate playfulness (Canisius College, 2015). 


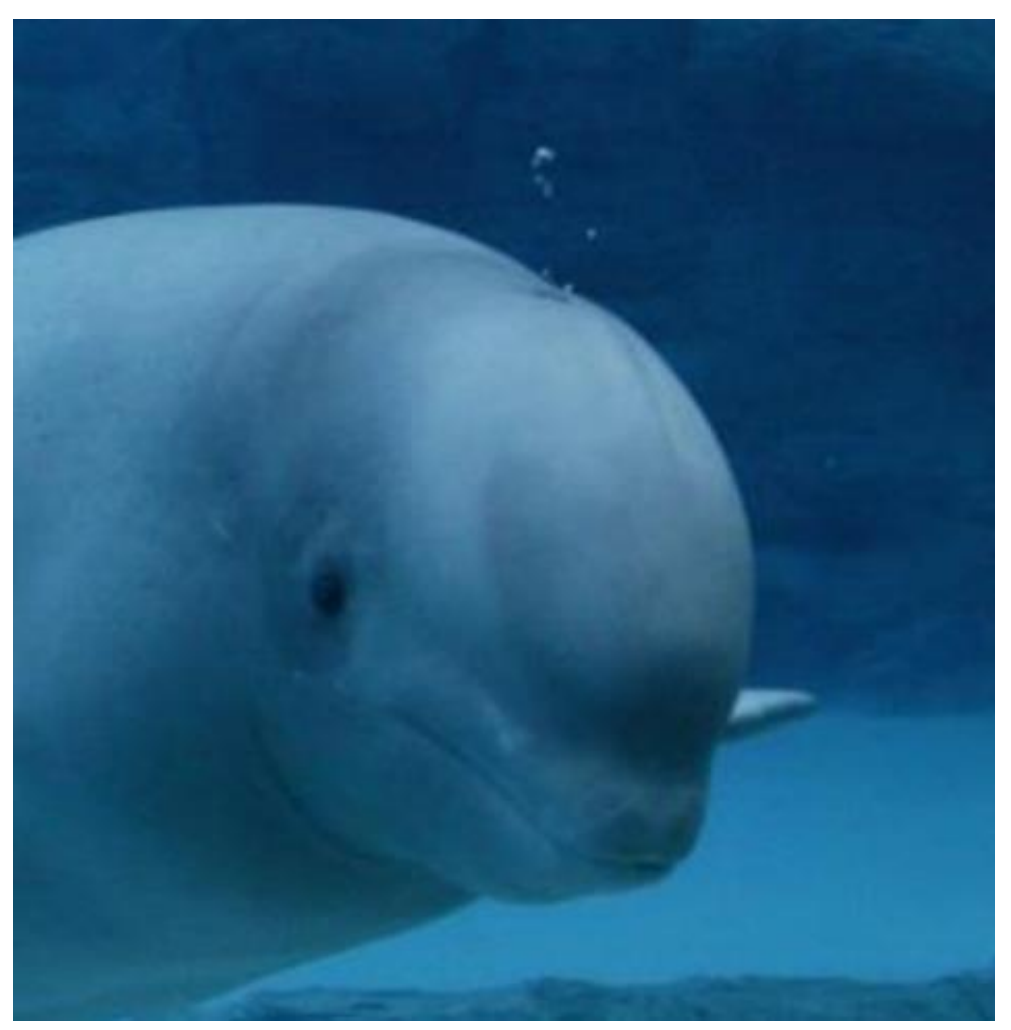

Figure 5. Blowhole Drip by a beluga whale. Photo courtesy of Michael Noonan, Canisius College.

\section{Mouth Bubble Cloud}

Unlike the other exhalations discussed in this review, which are emitted from the blowhole, another bubble emission is a release of air from the respiratory system channeled through the mouth (Baker \& Herman, 1984; Reidenberg \& Laitman, 2007). This emission occurs in humpback whales and is due to a unique physiological adaptation that allows them to move air from the respiratory to the digestive tract, despite their typical separation in cetaceans (Reidenberg \& Laitman, 2007). The resulting cloud of bubbles that exit the mouth between baleen likely has both feeding and social functions, though how it is used is currently unknown (Reidenberg \& Laitman, 2007). Additionally, this release of air from the mouth can occur simultaneously with bubble bursts or trails from the blowhole (Baker \& Herman, 1984; Reidenberg \& Laitman, 2007), indicating bubbles from the mouth may have an overlap in use with these other bubble types or modify other bubble signals.

\section{Conclusions}

The current literature on cetacean bubble production behaviors includes multiple terms per bubble type and reports that do not state or describe bubble type or combine types in their analysis or discussion. In this review, we have suggested terms with clear operational definitions that rely solely on the physical features of bubble type, which is crucial for comparisons across studies because it removes ambiguity and interpretation error. Additionally, we discussed alternate terms that have been used previously to refer to the same or similar bubble features in order to facilitate communication about these behaviors.

Gathering reports of bubble production across the literature has provided a general idea of the types of situations each bubble type are observed in and revealed multiple ways they are used. Bubble trails are seen in an assortment of contexts and are potentially used as an indication of stress, distress, or aversion, agonistic interactions, maintaining or initiating synchrony, and in conjunction with 
vocalizations as a multimodal signal. Observations of bubble bursts often suggest this production type is an agonistic response and an indication of surprise or interest. Bubble rings are primarily seen produced by cetaceans in managed care as a newly formed object to facilitate play. In addition, two reports have described this production type in the wild as a behavior used during aggressive contexts. Other bubble types have been documented but these are poorly understood and further research is needed to establish their function and relationship to other bubble types.

Opportunistic and anecdotal findings have built the foundation of our knowledge about bubble function, and given how little is known about bubble production, we encourage scientists to continue to report on bubble behaviors they come across during the course of their research. Additionally, empirical studies focused on bubble production behaviors are needed to support or refute current interpretations of bubble behaviors and untangle the details of how each type is used. For each bubble type, we have suggested possible studies to better understand their function. Because little is known regarding how much control individuals have over bubble production, a more complete understanding of the muscular control of air systems during vocalization and other activities, as well as its development, would also assist in understanding the functions of bubble production. We encourage both systematic observations and increased reporting of opportunistic sightings of these understudied behaviors.

Firmly demonstrating functions of bubble behaviors will allow us to make more informed conclusions in a variety of other studies, including acoustic, welfare, and conservation research. This will increase our understanding of communication behavior, particularly visual and multimodal communication. Most importantly, understanding bubble use is vital for appropriately interpreting behavioral responses. This is particularly valuable for welfare and conservation research. For example, knowing the function of bubble behaviors will provide more reliable metrics on how animals respond to provided enrichment, and whether these behaviors indicate increased welfare through engagement and investigation, or decreased welfare due to stress or a perceived threat. Another use of interpreting bubble responses is in assessing the effectiveness of new equipment to serve as deterrents or otherwise decrease negative human impacts, such as bycatch. Ultimately, we need to ensure our interpretations of observed behaviors are correct in order to be confident in our conclusions and implement best practices in welfare and conservation.

\section{Acknowledgments}

Thank you to Audra Ames for deep intellectual discussions that sparked the initial idea for investigating bubble production behavioral use, and for assistance in finding literature on the bubble trail whistle methodology. We are indebted to Diana Reiss for her insight into the evolutionary history of the bubble burst, and we thank her for insisting we look further into this connection. We are grateful for the extensive assistance of Erin Frick and Aly Taylor in finding the reports of bubble production scattered across the literature. Finally, thank you to Lauren Highfill, Lucas Keefer, Lisa Lauderdale, and two anonymous reviewers for their suggestions, edits, and encouragement along the many stages of this manuscript. This work was supported in part by the Zuckerman STEM leadership program.

\section{References}

Ames, A. E. (2016). Pre- and post-partum whistle production of a bottlenose dolphin (Tursiops truncatus) mothercalf dyad (unpublished master's thesis). University of Southern Mississippi, Hattiesburg, MS.

Ames, A. E., Zapetis, M. E., Witlicki, K. L., Wielandt, S. J., Cameron, D. M., Walker, R. T., \& Kuczaj II, S. A. (2017). Thunks: Evidence for varied harmonic structure in an Atlantic bottlenose dolphin (Tursiops truncatus) sound. International Journal of Comparative Psychology, 30. https://escholarship.org/uc/item/4489132c

Atkeson, T. D., Marchinton, R. L., \& Miller, K. V. (1988). Vocalizations of white-tailed deer. American Midland Naturalist, 120, 194-200.

Baker, C. S., \& Herman, L. M. (1984). Aggressive behavior between humpback whales (Megaptera novaeangliae) wintering in Hawaiian waters. Canadian Journal of Zoology, 62, 1922-1937. 
Beard, K. L. (2007). Use of bubble emissions by bottlenose (Tursiops truncatus) and Atlantic spotted dolphins (Stenella frontallis) relative to age and sex (unpublished master's thesis). University of Connecticut, Mansfield, CT.

Boisserie, J. R., Fisher, R. E., Lihoreau, F., \& Weston, E. M. (2011). Evolving between land and water: Key questions on the emergence and history of the hippopotamidae (Hippopotamoidea, Cetancodonta, Cetartiodactyla). Biological Reviews, 86, 601-625.

Bowles, A. E., \& Anderson, R. C. (2012). Behavioral responses and habituation of pinnipeds and small cetaceans to novel objects and simulated fishing gear with and without a pinger. Aquatic Mammals, 38, 161-168.

Bowles, A. E., Grebner, D. M., Musser, W. B., Nash, J. S., \& Crance, J. L. (2015). Disproportionate emission of bubble streams with killer whale biphonic calls: Perspectives on production and function. The Journal of the Acoustical Society of America, 137, EL165-EL170.

Bowles, A. E., Musser, W. B., Clark, K. F., Denes, S. L., \& Grebner, D. M. (2016). Perspectives on the function of behaviors synchronized with calling in female killer whales, Orcinus orca: Patterns of bubbling and nodding in bouts. International Journal of Comparative Psychology, 29. https://escholarship.org/uc/item/7590k51q

Canisius College. (2015, December 7). Belugas blow bubbles based on mood. Science Daily. Retrieved from www.sciencedaily.com/releases/2015/12/151207115317.htm

Cap, H., Deleporte, P., Joachim, J., \& Reby, D. (2008). Male vocal behavior and phylogeny in deer. Cladistics, 24, 917-931.

Cappiello, B. M., Hill, H. M., \& Bolton, T. T. (2018). Solitary, observer, parallel, and social object play in the bottlenose dolphin (Tursiops truncatus). Behavioural Processes, 157, 453-458.

Clark, F. E., Davies, S. L., Madigan, A. W., Warner, A. J., \& Kuczaj II, S. A. (2013). Cognitive enrichment for bottlenose dolphins (Tursiops truncatus): Evaluation of a novel underwater maze device. Zoo Biology, 32, $608-619$.

Delfour, F., \& Aulagnier, S. (1997). Bubbleblow in beluga whales (Delphinapterus leucas): A play activity? Behavioural Processes, 40, 183-186.

Delfour, F., \& Marten, K. (2001). Mirror image processing in three marine mammal species: Killer whales (Orcinus orca), false killer whales (Pseudorca crassidens) and California sea lions (Zalophus californianus). Behavioural Processes, 53, 181-190.

Dudzinski, K. M. (1996). Communication and behavior in the Atlantic spotted dolphins (Stenella frontalis): Relationship between vocal and behavioral activities (unpublished doctoral dissertation). Texas A\&M University, College Station, TX.

Dudzinski, K. M. (1998). Contact behavior and signal exchange in Atlantic spotted dolphins (Stenella frontalis). Aquatic Mammals, 24, 129-142.

Fertl, D., \& Wilson, B. (1997). Bubble use during prey capture by a lone bottlenose dolphin (Tursiops truncatus). Aquatic Mammals, 23, 113-114.

Fertl, D., \& Würsig, B. (1995). Coordinated feeding by Atlantic spotted dolphins in the Gulf of Mexico. Aquatic Mammals, 21, 3-5.

Frankel, A. S. (2018). Sound. In B. Würsig, J. G. M. Thewissen, \& K. M. Kovacs (Eds.), Encyclopedia of marine mammals, 3rd ed. (pp. 889-901). San Diego: Academic Press.

Fripp, D. (2005). Bubblestream whistles are not representative of a bottlenose dolphin's vocal repertoire. Marine Mammal Science, 21, 29-44.

Fripp, D. (2006). Bubblestream whistles are not representative of bottlenose dolphin whistle repertoires reply to Mccowan. Marine Mammal Science, 22, 496-501.

George, E. M., \& Noonan, M. (2016). Underwater bubbling in beluga whales (Delphinapterus leucas): Rates of production as a function of age, sex, and bubble type. Integrative and Comparative Biology, 56, E290-E290.

Gewalt, W. (1989). Orinoco-Freshwater-dolphin (Inia geoffrensis) using self-produced air bubble "rings" as toys. Aquatic Mammals, 15, 73-79.

Gnone, G., \& Moriconi, T. (2009). Use and function of distinctive whistle-like signals in bottlenose dolphin (Tursiops truncatus) mother-calf pair. In A. G. Pearce \& L. M. Correa (Eds.), Dolphins: Anatomy, behavior, and threats (pp. 149-167). New York: Nova Science Publishers, Inc.

Gnone, G., Pavan, G., Benoldi, G., Bonsignori, B., Manca, S., \& Manghi, M. (1996). Acoustic behavior of a captive newborn bottlenose dolphin. European Research on Cetaceans, 9, 65-68.

Gogoleva, S. S., Volodin, I. A., Volodina, E. V., Kharlamova, A. V., \& Trut, L. N. (2010). Vocalization toward conspecifics in silver foxes (Vulpes vulpes) selected for tame or aggressive behavior toward humans. Behavioural Processes, 84, 547-554. 
Graur, D., \& Higgins, D. G. (1994). Molecular evidence for the inclusion of cetaceans within the order Artiodactyla. Molecular Biology and Evolution, 11,357-364.

Greene, W. E., Melillo-Sweeting, K., \& Dudzinski, K. M. (2011). Comparing object play in captive and wild dolphins. International Journal of Comparative Psychology, 24, 292-306. https://escholarship.org/uc/item/7jn2q5c6

Hain, J. H. W., Carter, G. R., Kraus, S. D., Mayo, C. A., \& Winn, H. E. (1981). Feeding behavior of the humpback whale, Megaptera novaeangliae, in the western North Atlantic. Fishery Bulletin, 80, 259-268.

Hanna, P., Brown, B., Winship, K., Cameron, D., Hill, H., \& Kuczaj II, S. A. (2017). A killer whale's (Orcinus orca) response to visual media. International Journal of Comparative Psychology, 30. https://escholarship.org/uc/item/7060b9db

Helweg, D. A., Bauer, G. B., \& Herman, L. M. (1992). Observations of an s-shaped posture in humpback whales (Megaptera novaeangliae). Aquatic Mammals, 18, 74-78.

Herzing, D. L. (1996). Vocalizations and associated underwater behavior of free-ranging Atlantic spotted dolphins, Stenella frontalis and bottlenose dolphins, Tursiops truncatus. Aquatic Mammals, 22, 61-79.

Herzing, D. L. (2000). Acoustics and social behavior of wild dolphins: implications for a sound society. In W. Au \& R. R. Fay (Eds.), Hearing by whales and dolphins (pp. 225-272). New York: Springer.

Hill, H. M. (2009). The behavioral development of two beluga calves during the first year of life. International Journal of Comparative Psychology, 22, 234-253. https://escholarship.org/uc/item/2rs0c1nq

Hill, H. M., Dietrich, S., \& Cappiello, B. (2017). Learning to play: A review and theoretical investigation of the developmental mechanisms and functions of cetacean play. Learning \& Behavior, 45, 335-354.

Hill, H. M., Kahn, M. S., Brilliott, L. J., Roberts, B. M., Gutierrez, C., \& Artz, S. (2011). Beluga (Delphinapterus leucas) bubble bursts: Surprise, protection, or play? International Journal of Comparative Psychology, 24, 235-243. https://escholarship.org/uc/item/3q9669m4

Horback, K. M., Friedman, W. R., \& Johnson, C. M. (2010). The occurrence and context of s-posture display by captive belugas (Delphinapterus leucas). International Journal of Comparative Psychology, 23, 689-700. https://escholarship.org/uc/item/4zp4083k

Jones, B. L., \& Kuczaj II, S. A. (2014). Beluga (Delphinapterus leucas) novel bubble helix play behavior. Animal Behavior and Cognition, 2, 206-214.

Kennedy, M., Spencer, H. G., \& Gray, R. D. (1996). Hop, step and gape: Do the social displays of the Pelecaniformes reflect phylogeny? Animal Behaviour, 51, 273-291.

Kiley, M. (1972). The vocalizations of ungulates, their causation and function. Zeitschrift Für Tierpsychologie, 31, $171-222$.

Kuczaj II, S. A., Frick, E. E., Jones, B. L., Lea, J. S. E., Beecham, D., \& Schnöller, F. (2015). Underwater observations of dolphin reactions to a distressed conspecific. Learning \& Behavior, 43, 289-300.

Kuczaj II, S. A., Makecha, R., Trone, M., Paulos, R. D., \& Ramos, J. A. (2006). Role of peers in cultural innovation and cultural transmission: Evidence from the play of dolphin calves. International Journal of Comparative Psychology, 19, 223-240. https://escholarship.org/uc/item/4pn1t50s

Leiner, L., \& Fendt, M. (2011). Behavioural fear and heart rate responses of horses after exposure to novel objects: Effects of habituation. Applied Animal Behaviour Science, 131, 104-109.

Lilley, M. K., de Vere, A. J., Yeater, D. B., \& Kuczaj II, S. A. (2018). Characterizing curiosity-related behavior in bottlenose (Tursiops truncatus) and rough-toothed (Steno bredanensis) dolphins. International Journal of Comparative Psychology, 31. https://escholarship.org/uc/item/7sh5m0g8

Lusseau, D. (2006). Why do dolphins jump? Interpreting the behavioural repertoire of bottlenose dolphins (Tursiops sp.) in Doubtful Sound, New Zealand. Behavioural Processes, 73, 257-265.

Mackay, R. S., \& Liaw, H. M. (1981). Dolphin vocalization mechanisms. Science, 212, 676-678.

Mann, J., \& Smuts, B. (1999). Behavioral development in wild bottlenose dolphin newborns (Tursiops sp.). Behaviour, 136, 529-566.

Marten, K., Shariff, K., Psarakos, S., \& White, D. J. (1996). Ring bubbles of dolphins. Scientific American, 275, 8287.

McBride, A. F., \& Kritzler, H. (1951). Observations on pregnancy, parturition, and postnatal behavior in the bottlenose dolphin. Journal of Mammalogy, 32, 251-266.

McCowan, B. (2006). Are bubblestream whistles unrepresentative of bottlenose dolphin whistle repertoires? Marine Mammal Science, 22, 492-495.

McCowan, B., Marino, L., Vance, E., Walke, L., \& Reiss, D. (2000). Bubble ring play of bottlenose dolphins (Tursiops truncatus): Implications for cognition. Journal of Comparative Psychology, 114, 98-106. 
McCowan, B., \& Reiss, D. (1995). Whistle contour development in captive-born infant bottlenose dolphins (Tursiops truncatus): Role of learning. Journal of Comparative Psychology, 109, 242-260.

McCowan, B., \& Reiss, D. (2001). The fallacy of "signature whistles" in bottlenose dolphins: A comparative perspective of "signature information" in animal vocalizations. Animal Behaviour, 62, 1151-1162.

Mizuguchi, D., Tsunokawa, M., Kawamoto, M., \& Kohshima, S. (2016). Underwater vocalizations and associated behavior in captive ringed seals (Pusa hispida). Polar Biology, 39, 659-669.

Moreno, K. R. (2017). Cetacean exhalation: An xxamination of bottlenose dolphin (Tursiops truncatus) use of three bubble production types through associated behaviors (unpublished doctoral dissertation). University of Southern Mississippi, Hattiesburg, MS.

Morisaka, T., Shinohara, M., \& Taki, M. (2005). Underwater sounds produced by neonatal bottlenose dolphins (Tursiops truncatus): I. Acoustic characteristics. Aquatic Mammals, 31, 248-257.

Morton, E. S. (1977). On the occurrence and significance of motivation-structural rules in some bird and mammal sounds. The American Naturalist, 111, 855-869.

O'Leary, M. A., \& Gatesy, J. (2008). Impact of increased character sampling on the phylogeny of Cetartiodactyla (Mammalia): Combined analysis including fossils. Cladistics, 24, 397-442.

Overstrom, N. A. (1983). Association between burst-pulse sounds and aggressive behavior in captive Atlantic bottlenosed dolphins (Tursiops truncatus). Zoo Biology, 2, 93-103.

Pace, D. S. (2000). Fluke-made bubble rings as toys in bottlenose dolphin calves (Tursiops truncatus). Aquatic Mammals, 26, 57-64.

Paulos, R. D., Trone, M., \& Kuczaj II, S. A. (2010). Play in wild and captive cetaceans. International Journal of Comparative Psychology, 23, 701-722. https://escholarship.org/uc/item/3368z4tq

Pryor, K. W. (1990). Non-acoustic communication in small cetaceans: Glance, touch, position, gesture, and bubbles. In J. A. Thomas \& R. A. Kastelein (Eds.) Sensory abilities of cetaceans (pp. 537-544). Boston, MA: Springer.

Pryor, K. W., \& Kang, I. (1980). Social behavior and school structure in pelagic porpoises (Stenella attenuata and $S$. longirostris) during purse seining for tuna. Southwest Fisheries Center Administrative Report \#LJ-80-11C. La Jolla, CA: Southwest Fisheries Science Center.

Reidenberg, J. S., \& Laitman, J. T. (2007). Blowing bubbles: An aquatic adaptation that risks protection of the respiratory tract in humpback whales (Megaptera novaeangliae). The Anatomical Record, 290, 569-580.

Richardson, L. W., Jacobson, H. A., Muncy, R. J., \& Perkins, C. J. (1983). Acoustics of white-tailed deer. Journal of Mammalogy, 64, 245-252.

Shane, S. H. (1990). Behavior and ecology of the bottlenose dolphin at Sanibel Island, Florida. In S. Leatherwood \& R. R. Reeves (Eds.) The bottlenose dolphin. (pp. 245-265). San Diego, CA: Academic Press.

Sharpe, F. A., \& Dill, L. M. (1997). The behavior of Pacific herring schools in response to artificial humpback whale bubbles. Canadian Journal of Zoology, 75, 725-730.

Similä, T., \& Ugarte, F. (1993). Surface and underwater observations of cooperatively feeding killer whales in northern Norway. Canadian Journal of Zoology, 71, 1494-1499.

Slooten, E. (1994). Behavior of hector's dolphin: Classifying behavior by sequence analysis. Journal of Mammalogy, 75, 956-964.

Stoeger-Horwath, A. S., Stoeger, S., Schwammer, H. M., \& Kratochvil, H. (2007). Call repertoire of infant African elephants: First insights into the early vocal ontogeny. The Journal of the Acoustical Society of America, 121, 3922-3931.

Tembrock, G. (1976). Canid vocalizations. Behavioural Processes, 1, 57-75.

Trudelle, L. (2010). Dusky dolphin bubble emissions during foraging: Potential functions. MS internship report prepared at Texas A\&M University, Galveston, TX, for Centre d'Océanologie de Marseille, Université AixMarseille II, Marseille, France.

Tyack, P., \& Whitehead, H. (1982). Male competition in large groups of wintering humpback whales. Behaviour, $83,132-154$.

van der Woude, S. E. (2009). Bottlenose dolphins (Tursiops truncatus) moan as low in frequency as baleen whales. The Journal of the Acoustical Society of America, 126, 1552-1562.

Visser, I. N., Smith, T. G., Bullock, I. D., Green, G. D., Carlsson, O. G. L., \& Imberti, S. (2008). Antarctic peninsula killer whales (Orcinus orca) hunt seals and a penguin on floating ice. Marine Mammal Science, 24, 225-234.

Volodina, E. V., Volodin, I. A., Chelysheva, E. V, \& Frey, R. (2018). Hiss and snort call types of wild-living giraffes Giraffa camelopardalis: Acoustic structure and context. BMC Research Notes, 11. https://bmcresnotes.biomedcentral.com/articles/10.1186/s13104-017-3103-x

Wells, R. S., Scott, M. D., \& Irvine, A. B. (1987). The social structure of free-ranging bottlenose dolphins. Current Mammalogy, 1, 247-305. 
Wiley, D., Ware, C., Bocconcelli, A., Cholewaik, D., Friedlaender, A., Thompson, M., \& Weinrich, M. (2011). Underwater components of humpback whale bubble-net feeding behaviour. Behaviour, 148, 575-602.

Wood, F. G. (1953). Underwater sound production and concurrent behavior of captive porpoises, Tursiops truncatus and Stenella plagiodon. Bulletin of Marine Science of the Gulf and Caribbean, 3, 120-133.

Zaeschmar, J. R., Dwyer, S. L., \& Stockin, K. A. (2013). Rare observations of false killer whales (Pseudorca crassidens) cooperatively feeding with common bottlenose dolphins (Tursiops truncatus) in the Hauraki Gulf, New Zealand. Marine Mammal Science, 29, 555-562. 